\title{
Determination of feeding strategies in aquaculture farms using a multiple-criteria approach and genetic algorithms
}

\author{
Manuel Luna ${ }^{1}$ (D) $\cdot$ Ignacio Llorente ${ }^{1} \cdot$ Angel Cobo $^{2}$ \\ (c) Springer Science+Business Media, LLC, part of Springer Nature 2019
}

\begin{abstract}
Since the 1990s, fishing production has stagnated and aquaculture has experienced an exponential growth thanks to the production on an industrial scale. One of the major challenges facing aquaculture companies is the management of breeding activity affected by biological, technical, environmental and economic factors. In recent years, decisionmaking has also become increasingly complex due to the need for managers to consider aspects other than economic ones, such as product quality or environmental sustainability. In this context, there is an increasing need for expert systems applied to decision-making processes that maximize the economic efficiency of the operational process. One of the production planning decisions more affected by these changes is the feeding strategy. The selection of the feed determines the growth of the fish, but also generates the greatest impact of the activity on the environment and determines the quality of the product. In addition, feed is the main production cost in finfish aquaculture. In order to address all these problems, the present work integrates a multiple-criteria methodology with a genetic algorithm that allows determining the best sequence of feeds to be used throughout the fattening period, depending on multiple optimization objectives. Results show its utility to generate and evaluate different alternatives and fulfill the initial hypothesis, demonstrating that the combination of several feeds at precise times may improve the results obtained by one-feed strategies.
\end{abstract}

Keywords Aquaculture management · Operational research · Genetic algorithms · Multiple-criteria $\cdot$ Decision-making $\cdot$ Feeding strategies

Manuel Luna

manuel.luna@unican.es

1 Business Management Department, University of Cantabria, Santander, Spain

2 Department of Applied Mathematics and Computer Science, University of Cantabria, Santander, Spain 


\section{Introduction}

The exponential and uncontrolled growth of fisheries in the second half of the previous century put the sustainability of fish stocks at risk. Since the 1990s, fishing production has stagnated but there has been an exponential growth of aquaculture. Traditionally, marine fish farming was practiced extensively, mainly in lagoons and coastal ponds. However, production and consumption patterns have changed over time and, nowadays, intensive production is the most used method thanks to the development of new technologies. This change to intensive farming has led to the rapid development of the aquaculture industry, becoming a relevant industry around the world that is able to meet the demand for fish. In this context, sea cage farming has increased its importance in the aquaculture sector in which it has a major comparative and competitive advantage at a global level: the cost reduction, with no energy costs for pumping, aeration, or post-rearing water treatment. In contrast, similar to other areas of the primary sector, fish farms management is complex due to the broad range of internal and external factors that influence the decision-making process. In this way, main decisions throughout the breeding process are affected by the interactions of technical, biological, environmental and economic factors.

Over the last decades, operational research (OR) experts have already developed management tools and Decision Support Systems (DSSs) in order to respond to producers' demands on the automation and optimization of many strategic and operational decisions. In this regard, main company decisions have been also widely analyzed in many OR studies, such as site selection (Stagnitti 1997), facilities planning and design (Ernst et al. 2000) or hatchery management (Schulstad 1997). Most of these OR models applied in aquaculture have been traditionally based on accumulated experience in fishing and other primary sector activities, such as agriculture or forestry, to increase the efficiency and profitability of fish farming on an industrial scale (Bjørndal et al. 2004). These tools provide expert information in an easy-to-use manner to end users and, with the technological advance in Big Data and Artificial Intelligence, they have managed to improve aquaculture companies' capacity to make decisions and develop control systems (Zhou et al. 2018).

Among those decisions stands out the selection of the most suitable feeding strategy, since feed is the main operational cost in finfish aquaculture, which can achieve 30-60\% of total production costs (Goddard 1996). In this regard, great research efforts have been made to determine, from the manufacturer's point of view, the ingredients that would form the optimal feed formulation. This research effort is reflected in several review works, such as those carried out by Kousoulaki et al. (2015), summarizing the current knowledge about nutrition and feed management practices on European sea bass; Sørensen (2012), addressing how ingredient composition and processing conditions affect the fish quality; or De Verdal et al. (2017), analyzing past work to improve feed efficiency using selective breeding. Furthermore, many of these works apply optimization techniques to design an optimal diet composition as, for example, Hormiga et al. (2010) trying to ensure the maximal survival rate of Octopus vulgaris. However, in practice, most producers do not produce their own feed, but rather acquire the feed already formulated by the industry. This, in conjunction with the fact that there are a wide range of feeds in the market, implies that feeding strategies are a complex set of selections of different feeds for the fattening period, also called feeding paths, and, therefore, the number of potential possibilities is extensive and the results of those aspects can vary hugely depending on the final decision.

The central objective of this work is to provide decision makers with a model to address that combinatorial optimization problem. To this end, on the basis that feed selection 
depends on different factors at the precise moment at which feed is used and it is chosen among a finite set of alternatives provided by specialized manufacturers, metaheuristic techniques stand out as the best alternative to provide a solution. These techniques sacrifice the guarantee to find the optimal solution for the sake of getting good solutions in a significantly reduced amount of time (Blum and Roli 2003) compared to classic optimization techniques, many of whom are not applicable in these problems or lead to computation times too long for practical purposes. For these reasons, the present work applies a genetic algorithm (GA) to feeding decisions in order to generate and evaluate different feeding alternatives based on an objective function. GAs are metaheuristic search and optimization techniques based on principles present in natural evolution that are especially useful in this case since they are designed to work on large spaces involving states that can be represented by strings (Goldberg and Holland 1988), which is actually the best representation of a feeding path in aquaculture. Furthermore, they perform a multi-directional search by maintaining and combining a population of potential solutions (Michalewicz 1996), which allows greater flexibility and adaptability to producers' decisions.

GAs are one of the most popular heuristic approaches for optimization with application to many decision areas focused on process and product design, operations planning and control, and operations improvement, as stated in the bibliographical review carried out by Lee (2018). With regard to aquaculture, genetic algorithms have already been used successfully in different optimization problems, as well. Atia et al. (2012) used them to optimally design solar water heating systems and Liu et al. (2013) addressed the water quality prediction using a hybrid approach based on support vector regression and GAs. In this context, there are different applications that have integrated ecological factors in the optimization processes too, such as the prediction of the potential distribution of invader species (Chen et al. 2006), or the prediction of fish distributions (D’Angelo et al. 1995). Lastly, other nature-inspired metaheuristics have been also used successfully in various practical problems related to aquaculture, such as the determination of the production strategies that maximize the present profits of the farming process considering as decision variables the fingerlings size, seeding times and harvesting weights (Cobo et al. 2018). However, despite its application to different aspects of the activity, the enormous potential of these techniques to contribute to the improvement of the efficiency of the feeding decision-making process has still not been adequately exploited.

In this regard, there are still other challenges to be faced. Nowadays, producers should also attend to stakeholders' demands not only in terms of profitability or cost efficiency, but also in terms of environmental responsibility or product quality, aspects that they can sometimes find contradictory. This has led to a lack of management capacity due to the increasing complexity of those decisions and the need for extremely large amounts of data. Consequently, more and more producers demand expert's systems that take into account the new ways of production, such as cleaner production (CP) alternatives, integrating all these criteria with the aim of combining the efficient use of natural resources and the generation of economic profit (Vieira and Amaral 2016).

In accordance with that objective, the present study integrates a Multiple-Criteria Decision-Making (MCDM) methodology to formulate the fitness function that the genetic algorithm uses to evolve into a near-optimal solution. MCDM problems appear and are intensely applied in many domains where decisions have to be made in the presence of multiple objectives and criteria which usually are in conflict with each other (Tzeng and Huang 2011). In these situations, decision makers have to select, assess or rank the alternatives according to the weights of the criteria. In the present work, this methodology enables producers to design a feeding strategy according to their subjective perception of the relative 
importance of many criteria involved in the production process, such as economic, product quality or environmental sustainability ones. In the last decades the MCDM techniques have become an important branch of operations research (Triantaphyllou 2000; Figueira et al. 2005). Ishizaka and Labib (2011) have already shown the benefits of these methods in establishing rankings of alternatives through various experimental analysis. In addition, the emergence of new ways of production has led to the development of various MCDM tools applied to some problems of aquaculture, such as site selection (Dapueto et al. 2015; Shih 2017), planning of regional aquaculture development (El-Gayar and Leung 2001), the optimization of multi-objective bio-economic models in fisheries (Mardle et al. 2000) or the optimization of harvest management strategies of many species, considering interactions between and within species (Stafford 2008), but without analyzing the issue at hand.

The methodology developed in this work represents an innovation in aquaculture since it manages to integrate the use of various optimization criteria, crucial for the development of new ways of production, and the possibility of having a variable feeding path throughout the fattening process in the finfish-feeding decision-making process. After this introduction, the paper is structured as follows. First, Sect. 2 describes the methodological approach, combining MCDM techniques and GA. Then, although the developed methodology could be applied to the culture of many aquaculture species, it is tested in the case of gilthead seabream farming in sea cages in Sect. 3. Lastly, Sect. 4 discuss the results achieved and the conclusions and future research lines are given in Sect. 5.

\section{Materials and methods}

The problem addressed in this study is the determination of feeding strategies in aquaculture farms and, more specifically, in Gilthead seabream farms. For this purpose, a methodology that uses GA and MCDM methodologies has been developed. But, prior to the development of the methodology, the need for specific data and the complex relation between some variables made necessary to clarify the problem and the relational database used, which contains the multiple modules involved in decision-making process. Thus, the described methodology has been implemented in a tool that combines all the techniques required in order to carry out the collection of real data and the simulation and optimization process.

Intensive aquaculture presents good survival and growth rates and an acceptable operating margin compared to traditional extensive aquaculture, but farms management may be particularly difficult sometimes due to the technical, biological, environmental and economic factors that influence the main processes. In the case of Seabream, the production cycle should be divided into clearly defined phases, beginning with the larval rearing and then moving to fry rearing, both of which are conducted within the hatchery, and finally to on-growing (Brown 2003). The on-growing or fattening process can take place in cages, ponds or tanks, but the main system is the production in sea cages. This process starts by seeding juveniles in sea cages, with densities between 10 and $20 \mathrm{~kg} / \mathrm{m}^{3}$, that will be fed daily with a feed specifically designed for each species. In about 1 year, they are able to reach first commercial size ( $300 \mathrm{~g}$ ) but the exact duration of the breading process depends on many parameters such us the water temperature, some genetic characteristics or the feeding strategy, among others.

The feeding strategy is one of the most important decisions in aquaculture both for its high participation in the total cost of the company and for its influence on the growth of the 
fish and, therefore, on the future income. This decision implies a long process of research carried out by the feed manufacturers based on the search for an optimal feed formulation. However, when we refer to the feed selection process carried out by the producer, it can be defined as a combinatorial optimization problem, in which the producer has a finite set of feeds $\{F 1, F 2, \ldots, F m\}$ and the objective is to select the feed to be used in each week of the fattening period of the selected cage. The decision variables $x_{i} \in\{1,2, \ldots, m\}$ represent the feed used in week $i$, for $i=1,2, \ldots, n$ and a feeding path $X$ is a vector $X \in\{1,2, \ldots, m\}^{n}$. Results obtained for each feeding path are estimated based on the explanatory variables included in the bio-economic model, which will be explained later.

The use of an appropriate database is crucial to allow the tool to easily use specific information but also assists in the clarification of the problem by gaining a detailed understanding of the relationship between variables. In the present case, as can be seen in Luna et al. (2019), the database has a structure consisting of four groups of tables: First, a central axis to identify the aquaculture farm and its main characteristics. Then, two groups representing the uncontrollable variables, such as the water temperature or salinity, which cannot be manipulated by the decision maker, but do affect the system performance, and therefore are required for forming a reliable decision (Casini et al. 2015). Lastly, the group of tables containing the information about the current status of each cage and the specific feeding, growth and loss rates according to the available feeds.

Once the decision problem has been clarified, the methodology is structured as follows:

a. The first step to perform this process is to establish the criteria to be taken into account and weight each one based on the preferences of the farmer using MCDM techniques.

b. Secondly, prior to the process of optimization, the development of a bio-economic model is needed to reasonably simulate the results for each feeding strategy.

c. Lastly, an optimization process is developed based on a multiple-criteria fitness function according to which the initial population of feeding alternatives evolves, with the use of GA's crossover and mutation operators, until finding a useful solution.

\subsection{Criteria selection and weighting}

Within the supply of feed for the fattening process, there are notable differences in terms of prices, estimated growth rates and nutritional compositions. Furthermore, feeding strategies are conditioned by other factors, such as the environmental conditions of the farm or even the price variability, and it is therefore difficult to assess their subjective importance or the suitability of each feeding alternative.

\subsubsection{Proposed criteria}

Throughout this section, we explain the three groups of criteria (economic, environmental sustainability, and product quality) used in order to evaluate the feeding alternatives generated by the developed methodology. These criteria have been selected trying to accommodate most of the concerns of aquaculture producers when designing their feeding strategy. The final selection of criteria has been already explained on that published by Luna et al. (2019), where the use of each one and its suitability when selecting a single feed is explained in detail. However, in practice, this methodology allows decision-makers to choose only some of these factors for consideration or add new ones, before ranking them according to their individual needs. 
Traditionally, the main objective of most enterprises is profit maximization. Although there are several ways to measure the economic results of a company, in the present case the operational profit has been taken as a reference since it is a well-established and easy to interpret indicator. It is defined in the economic submodel as the difference between the costs incurred in the feeding process and the revenue obtained from the sales, calculated as a function of the average mass, its expected dispersion and the market price in dollars per $\mathrm{kg}$. The total weight in the cage is directly influenced by the growth, dispersion and mortality rates, so it will depend on the selected feed and the variations inherent to the fish source and species. Market prices considered are based on commercial classes, seasonal price and type of production (e.g. conventional or organic). This study considers only the feeding costs, making the assumption that others are not influenced by the chosen feed.

On the other hand, as an alternative to that conventional point of view, sustainable and organic procedures aim to reduce the negative environmental impacts of aquaculture production. In this regard, sharing best practices and their application in aquaculture companies throughout the breeding process is a key determinant, as well as the appropriate selection of feed producers, as they also use energy and emit carbon dioxide (Boyd 2015). The environmental sustainability criteria have been divided into three sub-categories:

- Official ecolabels have been designed to certify organic products from a trusted third party. The Commission Regulation (EC) No 889/2008 of 5 September 2008 have set specific rules on feeds for carnivorous aquaculture animals. They shall be sourced by-products from organic aquaculture, fisheries certified as sustainable or organic feed materials of plant origin (60\% maximum). Furthermore, the maximum stocking density is $15 \mathrm{~kg} / \mathrm{m}^{3}$ for sea bass and seabream. This label involves a disadvantage for the high cost of certification.

- In contrast, many consumers and producers prefer other strategies related to the environment surrounding aquaculture farms. Lembo et al. (2018) showed that in order to minimize the environmental impact of aquaculture, stakeholders placed the highest value on the prevention of nitrogen and phosphorus waste, and on the increase of feed efficiency in terms of fish meal and oil used. In this case, the feed efficiency is represented by the Fish-in Fish-out ratio, the amount of fish based feed needed to produce a unit weight of the cultured species.

- Along these lines, prior to the arrival to the farm, feed production has also an environmental impact that is commonly measured by the energy use (MJ equiv.), and the global warming potential impact $\left(\mathrm{CO}_{2}\right.$ equiv.) of the greenhouse gas emissions, among others (Abdou et al. 2017).

Lastly, fish products quality is easily perceived by the appearance, odor, flavor, and texture but it is still very difficult to contemplate objective criteria in this area. Several studies, such as Shahidi and Alasalvar (2010), have explained that fatty acids, particularly omega-3, are considered as health-promoting dietary components. In this regard, some feed producers present an approximate amount of omega-3 transmitted with the use of their feed during the whole fattening process based on their own empirical studies. Besides that, Grigorakis (2010) has shown that re-feeding fish that previously received plant oil with diets containing fish oil over a period of 90 days could be adequate to almost fully restore the initial muscle fatty acids in both gilthead seabream and sea bass. These two criteria have been included as an approach to two different points of view about the maximization of the fish quality.

Once selected, the corresponding criteria are organized into a hierarchical structure (Fig. 1) which will facilitate the evaluation of their relative importance. 


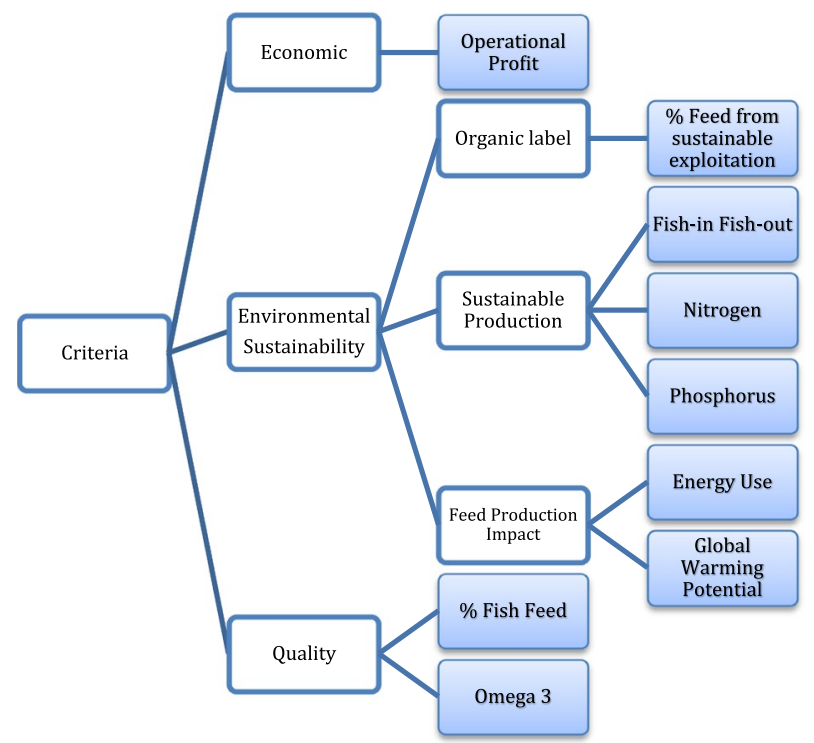

Fig. 1 Criteria hierarchy (Luna et al. 2019)

Table 1 AHP Marks Interpretation—Saaty (1987)

\begin{tabular}{|c|c|c|}
\hline Intensity & Importance of one over another & Explanation \\
\hline 1 & Equal importance & Two activities contribute equally to the objective \\
\hline 3 & Moderate importance & $\begin{array}{l}\text { Experience or judgment slightly favor one criterion over } \\
\text { another }\end{array}$ \\
\hline 5 & Essential or strong importance & $\begin{array}{l}\text { Experience or judgment strongly favor one criterion over } \\
\text { another }\end{array}$ \\
\hline 7 & Very strong important & $\begin{array}{l}\text { Activity is strongly favored and its dominance demonstrated in } \\
\text { practice }\end{array}$ \\
\hline 9 & Extreme importance & $\begin{array}{l}\text { The evidence favoring one activity over another is of the high- } \\
\text { est possible order of affirmation }\end{array}$ \\
\hline $2,4,6,8$ & Intermediate values & When compromise is needed \\
\hline
\end{tabular}

\subsubsection{Weighting method}

The developed methodology uses the Analytic Hierarchy Process (Saaty 1980) to turn human judgments in numerical values that will be easily integrated in a final weight for each criterion. That process is based on a series of pairwise comparisons, in which the decision-maker states his preferences by comparing all criteria and subcriteria with regard to same level decision elements, using a 1-9 numeric scale in order to establish priority values $a_{i j}$ for each pair of criteria (Table 1).

If the element $E_{i}$ is preferred to $E_{j}$ then $a_{i j}>1$. At each level of the criteria hierarchy an $n$-dimensional squared matrix, where the pairwise comparison values are stored, is obtained in which the reciprocal properties $a_{i j}=1 / a_{j i}, a_{i i}=1$ and $a_{i j}>0$ always holds. In such a way, each entry $\mathrm{a}_{\mathrm{ij}}$ represents the importance of the $i t h$ criterion relative to the $j t h$ criterion (1). 


$$
C=\left[\begin{array}{cccc}
1 & a_{12} & \ldots & a_{1 m} \\
1 / a_{12} & 1 & \ldots & a_{2 m} \\
\ldots & \ldots & 1 & \ldots \\
1 / a_{1 m} & 1 / a_{2 m} & \ldots & 1
\end{array}\right]
$$

Furthermore, the AHP model also proposes to estimates a measure of the consistency in the decision maker's judgments (Wang et al. 2007). The consistency analysis seeks to ensure that the judgments of the decision maker are coherent from a logical point of view. In order to contrast the consistency of comparative judgments between the criteria, Saaty (1980) defined an inconsistency ratio and recommends values of 0.1 or lower so that pairwise comparisons can be considered acceptable. Another consistency check is a weak consistency condition that checks whether if $a_{i j}>1$ and $a_{j k}>1$ then $a_{i k}>=\max \left(a_{i j}, a_{j k}\right)$ for every $i, j, k=1,2, \ldots, n$.

As simultaneously optimizing all the criteria is impossible, it is necessary to group these subjective judgments of the decision-maker on the importance of the criteria and from there define a heuristic process of searching for good solutions. In this regard, the developed methodology aggregates the values to form a vector of relative weights for each criterion considered in the matrix. In the present case, the weight vector is estimated as the normalized components of the eigenvector corresponding to the largest eigenvalue of the matrix, according to the Saaty's approach. To address that process, the application of the AHP methodology has been developed based on Cabral et al. (2016).

\subsection{Bio-economic simulation}

In order to simulate the fattening process for each alternative of feeding and estimate its results or consequences, a bio-economic model has been developed. In this regard, the bioeconomic model of the process of farming in sea cages integrated into the present work is based on the model proposed by Llorente and Luna $(2013,2014)$ and Cobo et al. (2015).

Initially, that model consisted in a biological sub-model of the process of farming in sea cages, which considers feed and growth rates as a percentage of the weight of the fish depending on the weight and environmental conditions, and an economic sub-model that quantifies the revenue and costs involved. However, MCDM techniques explore new factors, such as those related to environmental sustainability or product quality that affect the decision-making process in aquaculture. As a consequence, the bio-economic model has gone one step further to estimate every important factor, based on the characteristics of each feed, while the biological process is simulated. In this regard, it also takes the assumption that producers cannot address the control of any of the abiotic factors affecting the growth process, for example, temperature, light, salinity, and oxygen, in an economically efficient way (Brett 1979). Neither is it possible to choose the maximum biomass density, which is equal to the maximum insurable biomass density (Luna 2002) or to the maximum allowed density in the case of organic labelled production.

However, some different assumptions have been taken. First of all, now it is possible to change the feed during the fattening process in order to reach the farmer goals. In this way, some farmers use a different feed during the colder months trying to maintain the growth and mortality rates or to reduce costs. On the other hand, the model considers only one a time investment, in which producers will take the harvesting time decision attending to their economic needs or agreements, so harvesting weight will be slightly different for each 
feeding strategy. Nevertheless, this methodology is also adaptable to a different model that considers an infinite series of investments or time-dependent harvesting. In addition, the developed methodology allows decision-makers to consider, when such data is available, specific functions based on empirical findings in aspects such as feeding, growth, loss or dispersion.

Thus, feed composition and quality are considered crucial variables, dependent on the feed selected by the producer and the total amount consumed, since they will be used to simulate the economic, environmental and quality factors of each alternative on a daily basis. Finally, they are summed for the whole period getting as many values for each criterion as alternatives are generated in the optimization process.

\subsection{Optimizing feeding strategies}

Genetic algorithms are search algorithms based on the mechanics of natural selection and natural genetics. GAs starts with a random population of strings, known as chromosomes, and thereafter successive populations are generated. To perform an effective search for better and better structures, they first require payoff values (objective function values) associated with individual strings (Goldberg 2012).

In this regard, there are also different evolutionary metaheuristic techniques that can be used to address multiple-criteria problems, some of them using genetic algorithms such as NSGA-II (Deb et al. 2002). These techniques are mainly oriented to obtain a well-distributed set of non-dominated solutions that approximate the Pareto front in practical problems in a great variety of fields. In fact, evolutionary multi-objective optimization is one of the most active fields of research within evolutionary computation (Abraham et al. 2005).

However, evolutionary multi-objective algorithms usually require working with a small number of objectives, because when this number grows there is an exponential increase in the number of non-dominated solutions found by the algorithms, which blocks the mechanism they have to reach the solutions of the Pareto front (Ishibuchi et al. 2008). In practice, these evolutionary algorithms are not very useful for the resolution of problems with more than three objective functions, so in the present work, we have chosen to combine the objectives in a fitness function with an MCDM technique and thus approach the problem with GAs.

\subsubsection{Evaluation function}

Genetic algorithms require an optimization objective according to which the population evolves. The fulfillment of this objective is measured by the fitness function $F(X)$, which assigns a fitness value to each individual based on the parameters derived from its chromosome. In the present study, that function is built for each feeding path taking the Technique of Order Preference by Similarity to Ideal Solution (TOPSIS) as a reference (Hwang and Yoon 1981).

Traditionally, TOPSIS considers two hypothetical alternatives: one with the best values for all the attributes (the positive-ideal) and one with the worst values for all the attributes (the negative-ideal), to later apply the fitness function for each alternative. Based on the definition of those ideal solutions, depending on each producer's profile, it is possible to obtain a ranking of alternatives. The ranking of alternatives depends on the attainment of 
relative proximity indexes using a TOPSIS approach which allows us to construct the relative proximity intervals.

This fitness function is, therefore, defined as the relative closeness to the ideal solution:

$$
F(X)=\frac{d^{-}(X)}{d^{-}(X)+d^{+}(X)}
$$

where $d^{-}(X)$ and $\mathrm{d}^{+}(\mathrm{X})$ represents the separation of criteria values of $X$ from the negative ideal and positive ideal solutions, respectively. This ratio varies between 0 and 1 and alternatives with a ratio closer to 1 would be preferred. Accordingly, and from the best alternatives, the optimization algorithm continues generating new solutions in order to evolve to a near-optimal one (Lamata et al. 2016).

In the present study, a TOPSIS has been integrated in an evolutionary methodology. This causes that there are not a fixed number of combination or alternatives, but they are generated sequentially. In order to overcome this problem, two hypothetical ideal alternatives, positive and negative, are generated from an initial step where only one feed can be used during the whole period. This enables to estimate the initial values for each criterion, as many as feeds are available, and to generate the hypothetical alternatives with the best and worst values with a supplement of $\pm 75 \%$, assuming that a combination of different feeds will achieve better results than the utilization of only one. The only exception is the criterion of organic production feed ratio, whose ideal value is considered 1 and the antiideal value 0 .

\subsubsection{Evolving process}

Once the fitness function has been fixed, the process continues with the generation of a random set (population) of feeding paths (individuals) and an estimation of their fitness according to that evaluation function. The second step of the GA methodology is to improve the initial population sequentially. This algorithm receives three operators to guide the algorithm towards a solution to the given problem:

a. Selection: The selection process determines which individuals participate in reproduction to generate the next population according to their fitness values. In general, this process takes advantage of the fittest solutions by giving them greater weight when selecting the next generation and hence leads to better solutions to the problem (Siriwardene and Perera 2006).

The developed methodology includes an elitism factor. Elitist selection strategies ensure that a percentage of the fittest alternatives continue to the next generation without any crossover or mutation. Once again, the disadvantage is the possibility of genetic convergence but some studies have proven that elitism appears to be an important factor to improve evolutionary multiple-objective optimization (Parks 1996; Zitzler et al. 2000).

b. Crossover: the classic genetic crossover is performed using a random crossing point to create new individuals for the next generation by taking more than one parent solutions and combining them into a child solution. A high crossover rate encourages good mixing and the genetic algorithm is more likely to create a better solution.

c. Mutation operators. The mutation randomly changes the feed of a week encouraging genetic diversity amongst solutions. High mutation rates prevent GA from converging to a local minimum but it could destroy good solutions. 
Furthermore, to initiate the process it is necessary to assign the value of certain parameters, such as the crossover and mutation probabilities or the size of the population. The population size is the number of individuals that form part of each set generated. More individuals means more cost, in time, but also increase the population diversity.

During this process, each solution, therefore, needs to be awarded a score, to indicate how close it came to meeting the overall specification of the desired solution, by applying the fitness function (2). This score, allow the process to decide the optimum moment to stop, by a stopping criterion, instead of continuing during a fixed number of generations. The stopping criterion is settled as a number of generations without any improvement and when it is met, the algorithm provides the final set of feeding strategies.

Finally, the ranking of the alternatives is presented with information about the feed to be used each week and the values of each criterion in the final alternatives are provided to the decision maker.

\section{Application to gilthead seabream feeding strategies}

Once the methodology has been developed, the process of selecting the optimal feeding strategy has been tested for two theoretical scenarios on decision-makers' preferences. Results for the selected strategy in each of those scenarios will be simulated for the case of a gilthead seabream farm in the Mediterranean during a period of 52 weeks and with the possibility of using three different feeds currently available in the market. As will be explained below, information used has been collected from primary sources, such as oceanographic buoys or feed manufacturers, or secondary sources of information, i.e., other research studies.

Therefore, the simulation process starts with the collection of relevant data, both from the farm and from external factors, and the estimation of the final weights for all the criteria in each scenario. Secondly, an objective function is calculated with the bio-economic model. Then, the process of optimization is developed with the generation and evaluation of alternative feeding paths in order to find an optimum strategy. Lastly, as a discussion of the utility of this methodology, results for the first scenario are compared with the alternative of using only the most adequate feed.

\subsection{Farm information}

First of all, the specific characteristics of one farm of gilthead seabream have been simulated (Table 2) based on common characteristics of Mediterranean farms in Spain. In this way, the problem to optimize would be the performance of a unique sea cage of Gilthead seabream with juveniles of $30 \mathrm{~g}$ during a year. The maximum biomass density depends on the type of production as the regulation requires, generally being $20 \mathrm{~kg} / \mathrm{m}^{3}$ unless in the case of organic production where it would decrease to $15 \mathrm{~kg} / \mathrm{m}^{3}$.

External factors included in the database are the water temperature and the characteristics of the available feeds. Information on sea temperature has been collected from the oceanographic buoys network of the Spanish Port Authority, that covers the principal locations of marine aquaculture in Spain. In the present study, only the data registered during 2017 by the buoy placed at the simulated location, in the Mediterranean Sea near Tarragona (Fig. 2), have been used. 
Table 2 Farm characteristics

\begin{tabular}{lr}
\hline Parameter & \multicolumn{2}{l}{ Value } \\
\hline Seeding date & $15 / 06 / 2018$ \\
Harvesting date & $15 / 06 / 2019$ \\
Time horizon & 52 weeks \\
Cage capacity & $200 \mathrm{~m}^{3}$ \\
Juvenile weights & $30 \mathrm{~g}$ \\
Feasible harvest sizes & $(300,1000) \mathrm{g}$ \\
Location & Tarragona (2720) \\
\hline
\end{tabular}

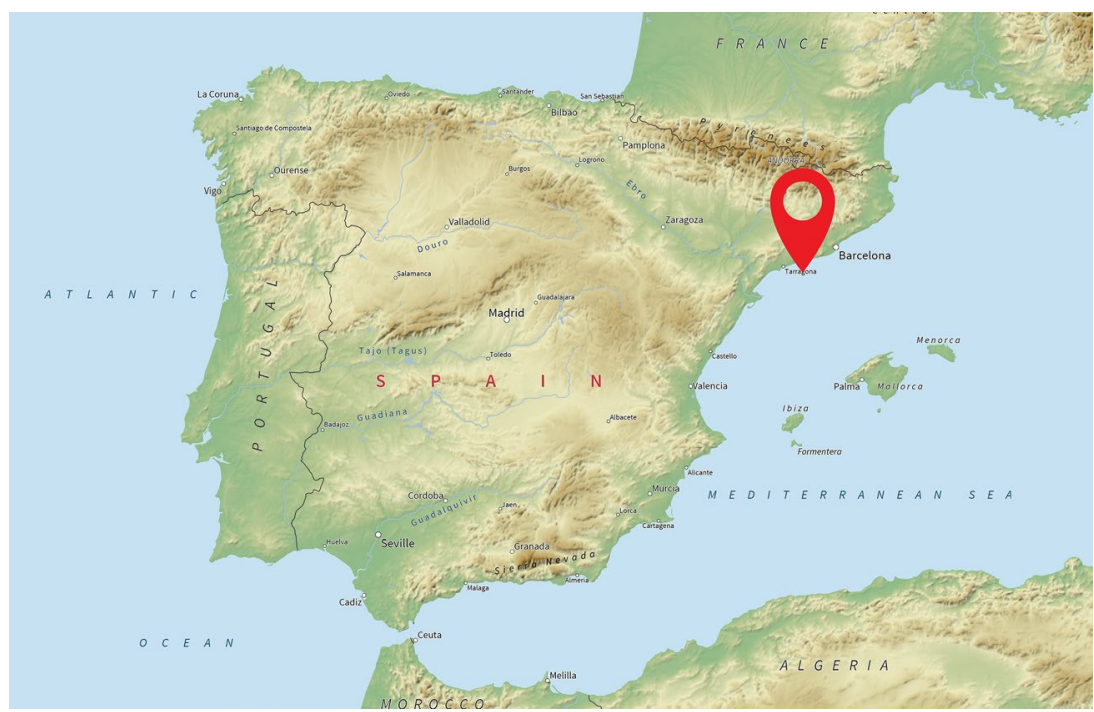

Fig. 2 Port Buoy 2720. Source: Mapswire

Regarding the feeding alternatives, the main rates and characteristics have been estimated based on the information provided directly by the feed producer (Table 3). However, there is one exception: feed production impact criteria have been estimated based on the study conducted by Pelletier and Tyedmers (2007). In that study, the approximate value for both "feed production impact criteria" depending on the feed ingredients as the aggregated impact in raw material production, processing and transportation stages. All this information has been obtained for three different feeds:

- Feed 1 (F1) represents the more commonly used feed since it performs well under normal circumstances and it is available at a very competitive price.

- Feed 2 (F2) have an increased percentage of fish protein so, although it has a higher price, growth rates are good even under unfavorable weather conditions.

- Feed 3 (F3) is a high quality and price feed, entirely made with products from organic fisheries/production. This feed presents always better results, especially in warm conditions. 
Table 3 Feeds info

\begin{tabular}{llll}
\hline Feed info & F1 & F2 & F3 \\
\hline Price USD/kg & 1.11 & 1.19 & 1.49 \\
Fish origin feed (\%) & 25 & 38 & 55 \\
Plant origin feed (\%) & 50 & 62 & 45 \\
Poultry origin feed (\%) & 25 & 0 & 0 \\
Organic feed (\%) & 0 & 0 & 100 \\
Total nitrogen (g per kg of feed) & 77.5 & 73.6 & 99 \\
Total phosphorus (g per kg of feed) & 16.3 & 16.8 & 17.5 \\
Energy use (MJ equiv. per kg of feed) & 19.451 & 9.422 & 24.815 \\
Global warming (kg CO equiv. per kg of feed) $_{\text {Omega-3 (g per kg of fish growth) }}^{1.665}$ & 0.800 & 1.705 \\
\hline
\end{tabular}

Table 4 Pairwise judgmentsmain groups

\begin{tabular}{|c|c|c|c|c|c|c|c|}
\hline & \multicolumn{3}{|c|}{ Scenario 1} & & \multicolumn{3}{|c|}{ Scenario 2} \\
\hline & $\mathrm{C}_{1}$ & $\mathrm{C}_{2}$ & $\mathrm{C}_{3}$ & & $\mathrm{C}_{1}$ & $\mathrm{C}_{2}$ & $\mathrm{C}_{3}$ \\
\hline $\mathrm{C}_{1}$ & 1 & 9 & 9 & $\mathrm{C}_{1}$ & 1 & $1 / 9$ & $1 / 2$ \\
\hline $\mathrm{C}_{2}$ & $1 / 9$ & 1 & 1 & $\mathrm{C}_{2}$ & 9 & 1 & 4 \\
\hline $\mathrm{C}_{3}$ & $1 / 9$ & 1 & 1 & $\mathrm{C}_{3}$ & 2 & $1 / 4$ & 1 \\
\hline \multicolumn{4}{|c|}{ Consistency Index $=0.0$} & \multicolumn{4}{|c|}{ Consistency Index $=0.0$} \\
\hline
\end{tabular}

$\mathrm{C}_{1}=$ Economic criteria; $\mathrm{C}_{2}=$ Environmental criteria; $\mathrm{C}_{3}=$ Quality criteria

\subsection{Theoretical scenarios of producer's preferences}

Once the main conditions have been specified, two theoretical scenarios of producer preferences have been simulated for such a farm. To estimate the final weights in each scenario, criteria are compared by pairs, scoring the importance of each criterion related to another one. In the present study, two conflicting tendencies have been analyzed with respect to fish production: the traditional production procedures with the only objective of maximizing the annual profit and the organic production trend commonly used to differentiate the product with an organic label, which constitute an alternative to conventional aquaculture.

The scoring process follows a hierarchical structure, starting from the big groups of criteria and ending on the disaggregated criteria. This system reduces the number of evaluations just to the values under the main diagonal inasmuch as the others are deducted by the property of reciprocity $\left(\mathrm{a}_{\mathrm{ji}}=1 / \mathrm{a}_{\mathrm{ij}}\right)$ :

- First of all, when comparing the three groups of criteria (Table 4), the economic criterion is evaluated with the highest value in the first scenario, while the group formed by the environmental sustainability criteria is the most important in the second one.

- Secondly, the environmental sustainability criteria have been evaluated in both scenarios. In the first one all the environmental criteria have low importance and only the fishin:fish-out stands out inasmuch as it represents an efficiency ratio. On the other hand, the criterion that has a more prominent weight in the second scenario is the proportion 
Table 5 Pairwise judgments-environmental sustainability criteria

\begin{tabular}{|c|c|c|c|c|c|c|c|c|c|c|c|c|c|}
\hline & \multicolumn{6}{|c|}{ Scenario 1} & & \multicolumn{6}{|c|}{ Scenario 2} \\
\hline & $\mathrm{C}_{2.1}$ & $\mathrm{C}_{2.2}$ & $\mathrm{C}_{2.3}$ & $\mathrm{C}_{2.4}$ & $\mathrm{C}_{2.5}$ & $\mathrm{C}_{2.6}$ & & $\mathrm{C}_{2.1}$ & $\mathrm{C}_{2.2}$ & $\mathrm{C}_{2.3}$ & $\mathrm{C}_{2.4}$ & $\mathrm{C}_{2.5}$ & $\mathrm{C}_{2.6}$ \\
\hline $\mathrm{C}_{2.1}$ & 1 & $1 / 9$ & $1 / 3$ & $1 / 3$ & $1 / 6$ & $1 / 6$ & $\mathrm{C}_{2.1}$ & 1 & 9 & 9 & 9 & 9 & 9 \\
\hline $\mathrm{C}_{2.2}$ & 9 & 1 & 3 & 3 & 2 & 2 & $\mathrm{C}_{2.2}$ & $1 / 9$ & 1 & 1 & 1 & 1 & 1 \\
\hline $\mathrm{C}_{2.3}$ & 3 & $1 / 3$ & 1 & 1 & $1 / 2$ & $1 / 2$ & $\mathrm{C}_{2.3}$ & $1 / 9$ & 1 & 1 & 1 & 1 & 1 \\
\hline $\mathrm{C}_{2.4}$ & 3 & $1 / 3$ & 1 & 1 & $1 / 2$ & $1 / 2$ & $\mathrm{C}_{2.4}$ & $1 / 9$ & 1 & 1 & 1 & 1 & 1 \\
\hline $\mathrm{C}_{2.5}$ & 6 & $1 / 2$ & 2 & 2 & 1 & 1 & $\mathrm{C}_{2.5}$ & $1 / 9$ & 1 & 1 & 1 & 1 & 1 \\
\hline $\mathrm{C}_{2.6}$ & 6 & $1 / 2$ & 2 & 2 & 1 & 1 & $\mathrm{C}_{2.6}$ & $1 / 9$ & 1 & 1 & 1 & 1 & 1 \\
\hline \multicolumn{7}{|c|}{ Consistency Index $=0.0027$} & \multicolumn{7}{|c|}{ Consistency Index $=0.0$} \\
\hline
\end{tabular}

$\mathrm{C}_{2.1}=$ Organic feed $(\%) ; \mathrm{C}_{2.2}=$ Fish-in fish-out; $\mathrm{C}_{2.3}=$ Total nitrogen $(\mathrm{g}) ; \mathrm{C}_{2.4}=$ Total phosphorus $(\mathrm{g})$; $\mathrm{C}_{2.5}=$ Energy use (MJ equiv.); $\mathrm{C}_{2.6}=$ Global warming ( $\mathrm{kg} \mathrm{CO}_{2}$ equiv.)

Table 6 Pairwise judgmentsproduct quality criteria

\begin{tabular}{lcrlllr}
\hline & \multicolumn{2}{c}{ Scenario 1 } & & \multicolumn{2}{c}{ Scenario 2 } \\
\cline { 2 - 3 } \cline { 5 - 7 } & $\mathrm{C}_{3.1}$ & $\mathrm{C}_{3.2}$ & & $\mathrm{C}_{3.1}$ & $\mathrm{C}_{3.2}$ \\
\hline $\mathrm{C}_{3.1}$ & 1 & $1 / 9$ & & $\mathrm{C}_{3.1}$ & 1 & $1 / 8$ \\
$\mathrm{C}_{3.2}$ & 9 & 1 & & $\mathrm{C}_{3.2}$ & 8 & 1 \\
Consistency Index $=0.0$ & & & Consistency Index $=0.0$ & \\
\hline
\end{tabular}

${ }^{*} \mathrm{C}_{3.1}=\%$ Fish origin feed $\mathrm{C}_{3.2}=$ Omega 3

of feed produced by organic production as requires the European Commission Regulation for the labeling of organic products (Table 5). In practice, this requirement will condition the final choice since only one feed fully complies it.

- Lastly, although a minimum quality is always required when selling fish products, quality criteria during the whole process are more important under the circumstances of differentiation, second scenario, than for a producer focused on economic performance as in the first scenario (Table 6).

After applying the AHP methodology, the weights associated with each criterion in each scenario are those shown in Table 7. As can be observed, the distribution of weights perfectly fulfils the perception of the relative importance of the criteria in the proposed scenarios. The feeding strategy selected for the first scenario will mainly depend on the economic benefit for the company, while in the second case, the most important criterion will be the achievement of an ecological label. This method greatly facilitates the evaluation work that could be very difficult to do directly on all of the criteria.

\subsection{Objective function}

In order to carry out the optimization process successfully, a fitness function, which evaluates how close a given solution is to the objective solution, is needed. In this particular 
Table 7 AHP weights in both scenarios considered

\begin{tabular}{lcc}
\hline Criterion & Scenario 1 (\%) & Scenario 2 (\%) \\
\hline Economic criteria & 81.8 & 8.3 \\
Profit & 81.8 & 8.3 \\
Environmental criteria & 9.1 & 75.0 \\
\% Organic feed & 0.3 & 48.2 \\
Fish-in fish-out ratio & 3.2 & 5.4 \\
Total nitrogen & 1.0 & 5.4 \\
Total phosphorus & 1.0 & 5.4 \\
Energy use & 1.8 & 5.4 \\
Global warming potential & 1.8 & 5.4 \\
Quality criteria & 9.1 & 16.7 \\
\% Fish origin feed & 0.9 & 1.9 \\
Omega 3 & 8.2 & 14.8 \\
\hline
\end{tabular}

case, the objective function is the business goal of the selected farm, in mathematical terms, of the multiple and competing criteria combined.

Both the process of estimation of the results for one feed alternatives in order to find the objective function and the evaluation of each alternative generated by the genetic algorithm involves two steps where the bio-economic model takes action. In the first instance, it estimates the growth reached and the feeding amount needed on a daily basis. Then, the value of each criterion is calculated from that data.

In economic terms, profit is quantified both in unitary and aggregated terms, by the revenue and costs involved. Cost varies as a function of the used feeds, due to its different feeding amount and price. Meanwhile, revenue depends on the reached growth, its dispersion if available and the selling price, which relies on the type of production. For classical aquaculture, weekly selling prices correspond to the main Spanish wholesale market prices for the commercial classes of Seabream (300-400 g, 400-600 g, $600-1000 \mathrm{~g}$ ) in 2018 . The prices are reduced by the average wholesale-producer margin as stated by MAPAMA (2012) and used as a proxy of the ex-farm price. In the case of organic aquaculture, Zander and Feucht (2017) have shown that the willingness to pay varies between $7 \%$ and almost $20 \%$, depending on attribute and country. Therefore, the used price is on average a $15 \%$ higher than in classical aquaculture for the same period.

In the case of all other additional criteria mentioned above, grouped as environmental sustainability and product quality criteria, they can be estimated based on the information provided by the different feed producers as a percentage of the amount used of each feed.

As a result of this process, the main values for each alternative are estimated. Data shown in Table 8 for the first scenario provides an idea of the importance of choosing an adequate feeding path, being able to distinguish clearly different results for each criterion. These results confirm the characteristics of the three different feed mentioned above. In the case of positive-ideal and negative-ideal, they are multiplied by $\pm 75 \%$ setting the objective functions. On the other hand, scenario two shows similar results with a reduction due to the smaller number of fishes seeded to meet the organic regulation requirements. 
Table 8 hypothetical ideal alternatives for scenario 1

\begin{tabular}{lllllll}
\hline Criterion & Obj & F1 & F2 & F3 & + Ideal & - Ideal \\
\hline $\begin{array}{l}\text { Economic criteria } \\
\text { Profit (\$) }\end{array}$ & MAX & 9921.03 & 9613.06 & 8067.96 & 17,361 & 2016 \\
$\begin{array}{l}\text { Environmental criteria } \\
\text { Organic feed (\%) }\end{array}$ & MAX & $0 \%$ & $0 \%$ & $100 \%$ & 1 & 0 \\
Fish-in fish-out ratio & MIN & $52 \%$ & $77 \%$ & $105 \%$ & $13 \%$ & $183 \%$ \\
Total N (g) & MIN & $650,069.23$ & $604,280.52$ & $567,337.66$ & 157,912 & $1,585,360$ \\
Total P (g) & MIN & $136,724.24$ & $137,933.60$ & $100,286.96$ & 34,181 & 280,240 \\
Energy use (MJ equiv.) & MIN & $163,154,800$ & $80,861,140$ & $227,074,800$ & $2.02 \mathrm{E}+07$ & $3.97 \mathrm{E}+14$ \\
Global warming (kg CO 2 equiv.) & MIN & $13,966,000$ & $6,865,731$ & $15,601,950$ & $1.72 \mathrm{E}+06$ & $2.73 \mathrm{E}+13$ \\
Quality criteria & & & & & & \\
\% Fish origin feed & MAX & $25 \%$ & $38 \%$ & $55 \%$ & $96 \%$ & $6 \%$ \\
Omega 3 (\%) & MAX & $1.02 \%$ & $1.49 \%$ & $1.73 \%$ & $3.50 \%$ & $0.25 \%$ \\
\hline
\end{tabular}

Table 9 Simulation numbers

\begin{tabular}{llll}
\hline Scenario & Generations & $\begin{array}{l}\text { Number of } \\
\text { alternatives }\end{array}$ & Execution time (s) \\
\hline First & 64 & 1920 & 293.25 \\
Second & 68 & 2040 & 333.65 \\
\hline
\end{tabular}

Then, as stated in the methodological approach, the fitness is calculated as the relative closeness to those ideal solutions (2).

\subsection{Search for useful solutions}

Once the objective function and the method responsible for evaluating each alternative of the feeding strategy have been determined, the genetic optimization process begins with the search of useful solutions, based on the generation of alternatives and the evolution till the point where a better solution is not found in a determined number of generations. For the evolving process, the following parameters have been considered: population size of 30 , crossover probability of 0.8 , mutation probability of 0.03 and a limit of 15 generations without any improvement to stop the process. Furthermore, the best individual is always included in the next generation.

After applying the genetic algorithm with the parameter defined above a set of 30 potential solutions is obtained for each generation, which means that more than 1900 alternatives for each scenario have been evaluated. This means that, in most cases, one of the problems faced by this type of tools is the computational cost, measured as the time needed to finish the process. But, in the present work, results have been obtained using an Intel Core i7 $2.81 \mathrm{GHz}$ processor and $16 \mathrm{~Gb}$ SDRAM, and the average execution time was only $210 \mathrm{~s}$ (Table 9). 

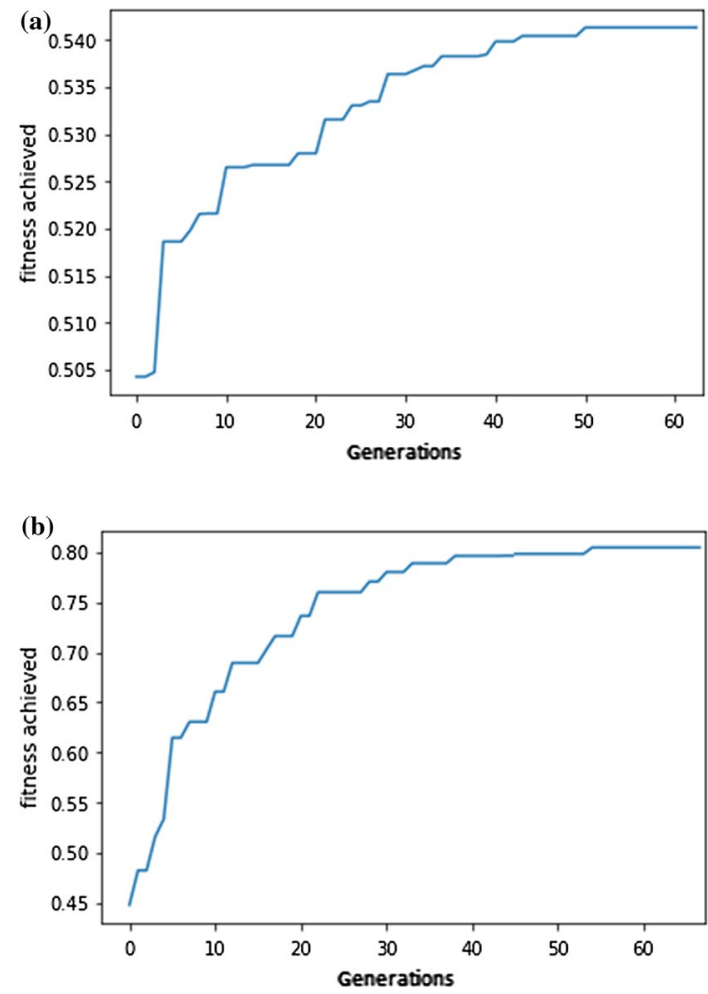

Fig. 3 a Evolution of the average fitness for scenario 1. b Evolution of the average fitness for scenario 2

Regarding the proper functioning of the evolutionary process, as can be seen in Fig. 3a, $\mathrm{b}$, in both cases the genetic algorithm has managed to show some improvement in the fitness quality (relative closeness to the ideal solution) of the feeding alternatives.

With respect to the fitness value and how it has been achieved, although both scenarios start from an intermediate value corresponding to the first randomly generated alternatives, there are some differences between them. While the first scenario seems to improve the fitness only a little bit after 60 generations (Fig. 3a), in the second one a relevant improvement is achieved (Fig. 3b). However, this does not necessarily mean that results for the second scenario are better than for the first one, but that it has managed to get closer to the option proposed in that scenario as the ideal one.

In addition, the algorithm provides the decision maker with the best feeding strategy generated during the iterative process (Table 10) and the final set of 30 potential solutions. This allows the decision-maker to compare the new feeding strategy, obtained with the option of combining different feeds along the breading process, with the traditional one-feed alternatives and results of each of them for the economic, environmental and quality criteria can be analyzed. Furthermore, the fact of offering to the decisionmaker a set, or population, of good alternatives or near-optimal schedules facilitates the final decision and allows considering new factors not initially included in the model.

The feeding strategy proposed for each scenario can be seen more graphically in Fig. 4a, $\mathrm{b}$, which shows the evolution of the water temperature (left side) over the whole period and the recommended feed (right side) for each week. 
Table 10 Best solutions for both scenarios

\begin{tabular}{lll}
\hline Scenario & Best solution-feeding path & Fitness \\
\hline First & $\{$ F3, F3, F3, F3, F3, F3, F3, F3, F3, F3, & 0.54218 \\
& F3, F1, F3, F1, F3, F1, F3, F2, F1, F1, & \\
& F1, F1, F1, F3, F2, F2, F1, F1, F1, F1, & \\
& F1, F1, F1, F1, F2, F1, F2, F2, F2, F2, & \\
& F2, F2, F2, F2, F2, F2, F2, F2, F2, F2, & \\
& F2, F2 $\}$ & \\
Second & $\{$ F3, F3, F3, F3, F3, F3, F3, F3, F3, F3, & 0.8028 \\
& F3, F3, F3, F3, F3, F3, F3, F3, F1, F3, \\
& F3, F3, F3, F3, F3, F3, F2, F3, F3, F3, \\
& F1, F3, F3, F3, F3, F3, F3, F3, F3, F3, \\
& F3, F3, F3, F3, F3, F3, F3, F3, F3, F3, \\
& F3, F3 & \\
\hline
\end{tabular}
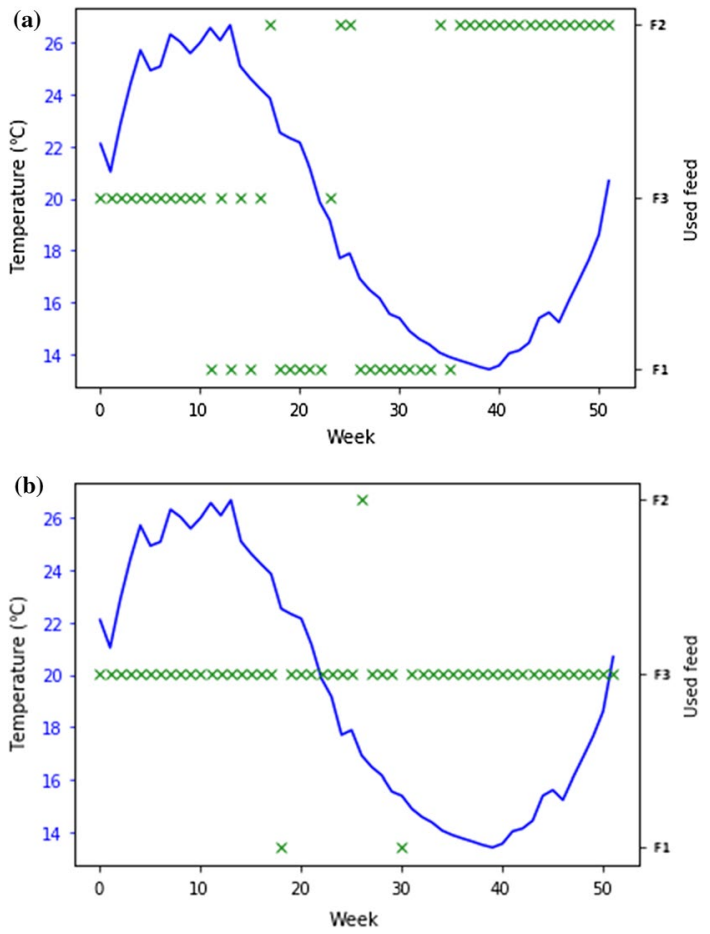

Fig. 4 a Selected feed and weekly temperature scenario 1. b Selected feed and weekly temperature scenario 2

In this regard, the best alternative for the first scenario is a mix of the three feeds (Fig. 4a). The algorithm recommends first the F3 feed, probably due to its better growth rates in warm conditions, but it changes to F2 feed, which has similar results under cold conditions, when the water temperature decreases. In the mid-term it recommends the cheaper one, generating a saving in feeding costs. In this case, although the ideal solution seems not to be very close, it can be assured that the best alternative is a combination of several feeds to take advantage of their qualities at each moment of the process.

However, in the second scenario (Fig. 4b) the algorithm mainly recommends the use of F3, since it is the only available feed that can be used for organic production. This explains 
why the ideal alternative and the solution reached are closer than in the other case, since both refer mainly to the criterion of organic labelling. This allows us to conclude that in a scenario like this, in which the producer needs to fulfil a specific requirement, the number of valid feeding alternatives is greatly reduced and the evolutionary process would simply lead to the option in which only the feed that comply with that requirement is used.

These results confirm that the methodology developed is useful when setting a production objective in a complex environment where diverse and sometimes conflicting criteria intervene. In addition, the fitness function and the genetic algorithm have worked at the time of optimizing feeding strategies, evolving from the first generation and finding a good solution in an adequate time.

\section{Discussion of the mixed strategy selected for the first scenario}

After assessing the capacity of the developed methodology to analyze and prioritize new alternatives properly, some features that are relevant shall be discussed thoroughly. The most important is the validation of the hypothesis that a combination of different feeds should improve the results obtained with only one feed during the whole period. This requires a comparison between the selected mixed strategy for the first scenario and the unique feed that the tool would have chosen if so requested. Secondly, the stability and sensibility of the outcomes that the developed methodology obtains have been tested. It should be taken into account that there is no point in discussing the results for scenario 2 , corresponding to organic production, since the methodology has led to the use of a onefeed strategy.

On the one hand, results for the first scenario are conclusive, the mixed strategy found by the developed methodology has resulted in significant gains in the improvement of the selected criteria, therefore confirming the initial hypothesis. In this case, the criterion with the highest importance is the economic one and it shows an improvement of $7.17 \%$ compared to the value estimated for F1 feed. As can be seen in Table 11, although there has been an increase in producer's costs, the increase in the weight achieved, and therefore in the benefits obtained, compensates the situation. Furthermore, product quality, where the second most important criterion can be found, becomes significantly larger. However, the results for the environmental sustainability criteria, which are not very important in this case, have worsened.

This results can be more easily compared in Fig. 5. As an added benefit, it is possible to highlight that the company can't sell the fish until they reach the minimum weight for sale in the market ( $300 \mathrm{~g})$ and in this case, it is reached several weeks before with the mixed strategy. This would give the producer greater flexibility and the capacity to react to possible adverse situations, which can be considered a measure that significantly reduces the risk incurred.

On the other hand, the proper functioning of the genetic algorithm has been analyzed in two steps: First, 100 executions were carried out with the initial parameters, described in the previous section, in order to evaluate the stability of the results obtained. This analysis allows us to test the ability of GA to reach a similar feeding alternative.

Regarding the fitness reached at the different times, there can be assurance that, as long as the current conditions are maintained, the feeding alternative selected will reach a similar fitness, resulting in the above mentioned increase in the company results (Table 12). 
Table 11 Improvements achieved-scenario 1

\begin{tabular}{|c|c|c|c|c|}
\hline Scenario 1 & $\mathrm{~F} 1$ & Mixed strategy & Var. & Result \\
\hline Fishes & 12,141 & 12,144 & $0.02 \%$ & Improvement \\
\hline Unit weight reached & 329.28 & 370.19 & $12.42 \%$ & Improvement \\
\hline Total weight (kg) & 3997.82 & 4496 & $12.45 \%$ & Improvement \\
\hline Cost $(\$)$ & 9341.17 & $11,028.29$ & $18.06 \%$ & Worsening \\
\hline Cost per kg & 2.06 & 2.16 & $4.99 \%$ & Worsening \\
\hline Revenue (\$) & $19,262.20$ & $21,660.39$ & $12.45 \%$ & Improvement \\
\hline Revenue per kg & 4.82 & 4.82 & - & - \\
\hline FCR $(\%)$ & $210 \%$ & $192 \%$ & $-8.50 \%$ & Improvement \\
\hline \multicolumn{5}{|l|}{ Economic criteria } \\
\hline Profit (\$) & 9921.03 & $10,632.10$ & $7.17 \%$ & Improvement \\
\hline \multicolumn{5}{|l|}{ Environmental criteria } \\
\hline Organic feed (\%) & $0 \%$ & $25 \%$ & $(+25 \%)$ & Improvement \\
\hline Fish-in fish-out ratio & $52 \%$ & $75 \%$ & $42.94 \%$ & Worsening \\
\hline Total N (g) & $650,069.23$ & $722,507.69$ & $20.90 \%$ & Worsening \\
\hline Total P (g) & $136,724.24$ & $149,525.28$ & $11.14 \%$ & Worsening \\
\hline Energy use (MJ equiv.) & $163,154,800$ & $151,911,800$ & $1.98 \%$ & Worsening \\
\hline Global warming ( $\mathrm{kg} \mathrm{CO}_{2}$ equiv.) & $13,966,000$ & $12,036,020$ & $8.55 \%$ & Worsening \\
\hline \multicolumn{5}{|l|}{ Quality criteria } \\
\hline$\%$ Fish origin feed & $25 \%$ & $39 \%$ & $56.22 \%$ & Improvement \\
\hline Omega $3(\%)$ & $1.02 \%$ & $1.27 \%$ & $24.99 \%$ & Improvement \\
\hline
\end{tabular}
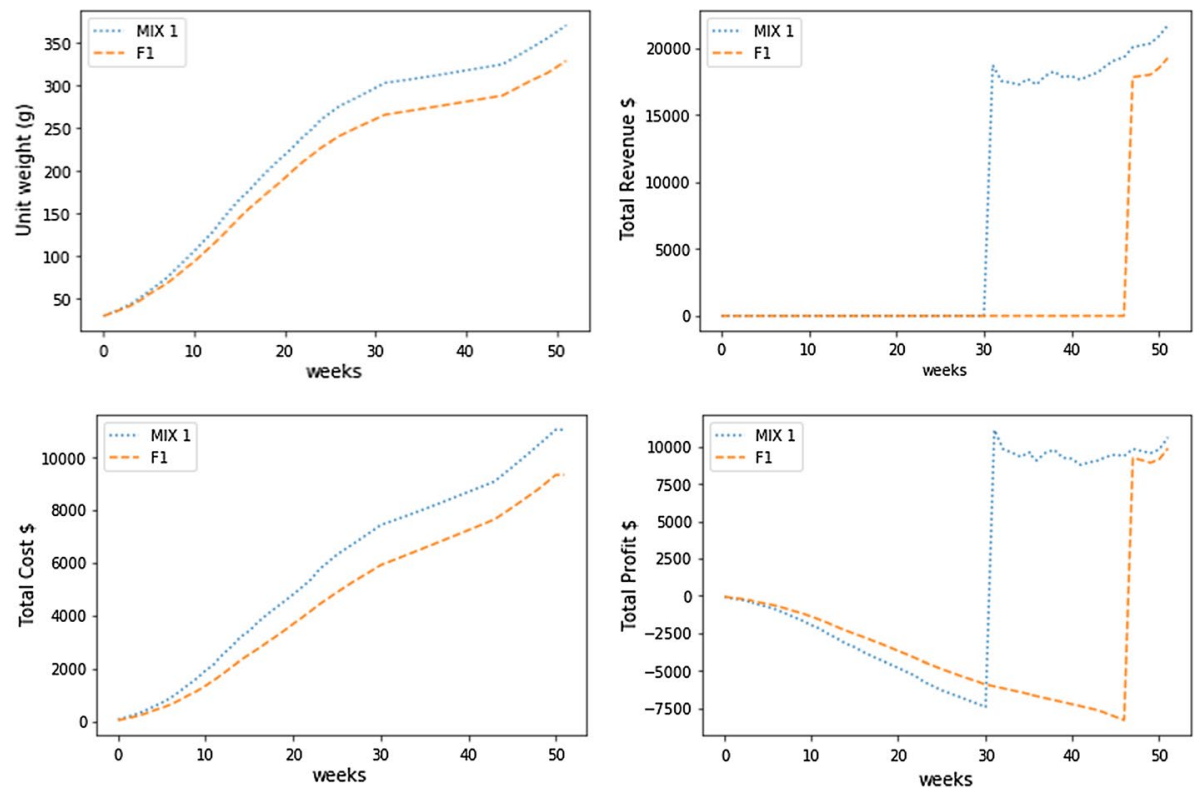

Fig. 5 Visual comparison of strategies-scenario 1 
Table 12 Stability analysis

\begin{tabular}{lllll}
\hline Runs & Mean & Std deviation & Max & Min \\
\hline 100 & 0.5428 & 0.0016 & 0.5467 & 0.5378
\end{tabular}

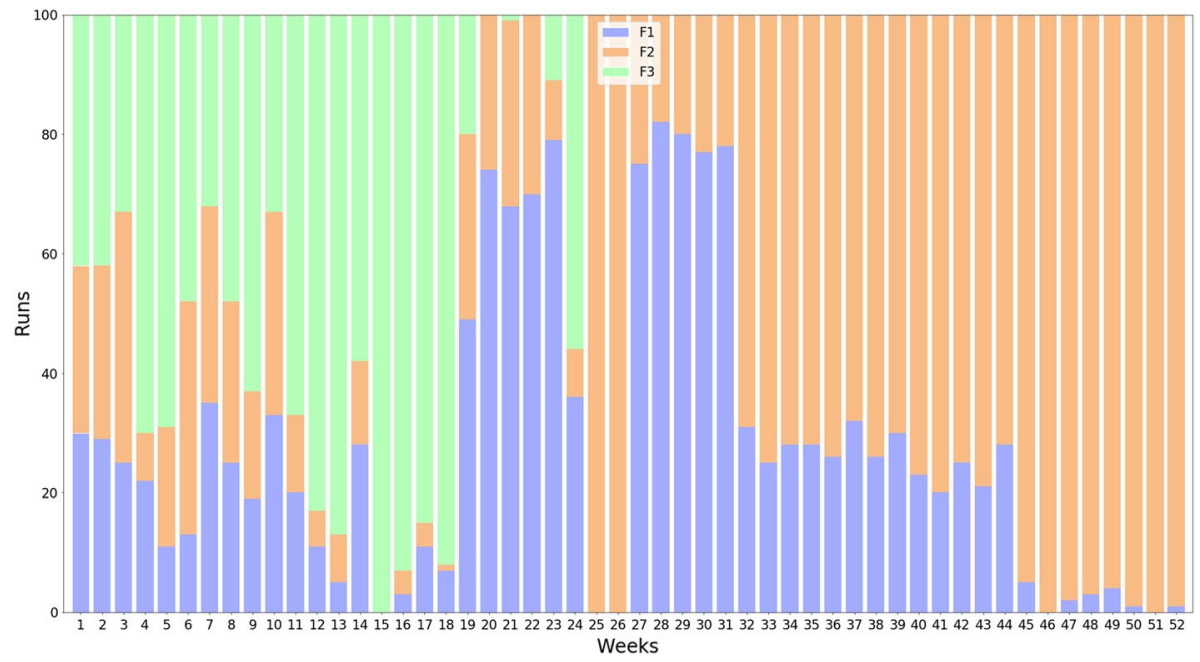

Fig. 6 Number of runs out of 100 in which each feed has been chosen

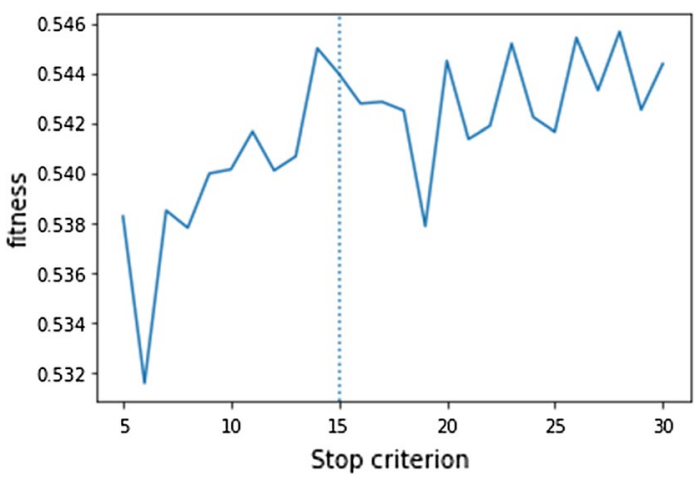

Fig. 7 Sensibility analysis

In addition, it is also possible to check that most feeding alternatives selected by the evolutionary process, in the 100 executions carried out, follow the similar pattern: a first phase using the F3 followed by a short phase of use of the F1, and a final phase where the vast majority of alternatives uses the F2. For this purpose, the Fig. 6 shows the how many times each feed has been chosen in each week. In this analysis, although the stability of the evolutionary search process is confirmed, it can be seen that in each phase there are some loose weeks in which a different feed is chosen. In practice, this type of outliers should be eliminated, either automatically or manually by the decision maker, given the inefficiency of changing feed for such a short period (1 week). 
Secondly, in order to analyse the sensitivity, how a small change in the operators to guide the algorithm could change the fitness reached was evaluated. In this case, a change in the stop criterion, the limit of executions without finding a better alternative, has been analyzed. As can be seen in the Fig. 7, although the results are made worse when the stop criterion is very low, the fitness variation is very low and there is a point, around 15 generations, when the fitness is stabilized.

These results have allowed us to set the stop criterion in 15 generations, obtaining good results without unnecessarily increasing the execution time, which could lead to inefficiencies. This analysis has been carried out both for the case of the total number of executions and the number of individuals per generation, with similar results. That points out to future applications of this methodology, where the value of these parameters could be optimized simultaneously in order to find the values that can find the optimal solution in the shortest amount of time, thus increasing the efficiency.

\section{Conclusions}

In recent years, aquaculture has become a relevant industry called to meet the world demand for fish, though not without difficulty. As is the case with many primary sector activities, the management of fish farms is increasingly complex due to the broad range of internal and external factors that influence most decisions and the need for managers to consider aspects other than economic ones, such as product quality or environmental sustainability. For all of these reasons, the need for more efficient and productive management systems in order to automate and optimize many strategic and operational decisions has increased over the last few years.

Among these decisions, it is possible to highlight the selection of the most suitable feeding strategy. These decisions are of greater importance not only because of the direct effect on the breeding costs they have, since feed is the main operational cost in in finfish aquaculture, but also because of they are the maximum responsible for the quality of the final product and the effect on the environment that surrounds the farm, two of the criteria most valued by stakeholders. Furthermore, feeding decisions have an added complexity: The existence of many different feeds and the possibility of combining them during the fattening process cause that traditional optimization techniques are not applicable to this problem or lead to computation times too long for practical purposes.

In order to address this problem, the present work integrates a multiple-criteria methodology with an evolutionary metaheuristic technique that allows determining the best sequence of feeds to be used throughout the fattening period, depending on multiple optimization objectives. In spite of their wide applicability and simplicity, metaheuristic techniques are not being used in the management of aquaculture farms as widely as in other contexts. In particular, genetic algorithms are well suited to address complex problems that arise in the management of such farms. In this regard, this work states a model in which the preferences of the decision maker are included thanks to the AHP methodology and these preferences influence the definition of the fitness function that a genetic algorithm subsequently uses.

In this regard, the main results of the simulations carried out seem to confirm the goodness of the model for the determination of feeding strategies in aquaculture farms that are affected by variations in environmental conditions. In addition, these results help to confirm that the combination of several commercial feeds in the same feeding strategy may 
improve the results obtained by one-feed strategies that considers only one commercial feed along all the production process.

In the context of the management of aquaculture companies, the implementation of the developed model allows multiple criteria to be introduced in the decision-making process, thereby enabling producers to find solutions suited to their needs from the many alternatives in very short time. All this is translated in a contribution to the improvement of the efficiency and flexibility of the decision-making processes, both regarding operative and strategic decisions.

From the point of view of the management of production processes, the proposed model allows to identify the feeding strategy that optimize the economic performance of the farm. However, and different from previous works that only considered the economic criteria in the decision process, this model also opens the door for aquaculture managers to find the feeding strategy that provides the best results in terms of environmental sustainability or product quality. Considering several criteria in the same decision is not a minor issue. As in other production activities, those criteria in aquaculture are very often opposed and, in most of the cases, their importance is based on the subjective perception attributed by each manager. In such way, this model integrates multiple-criteria decision making techniques and genetic algorithms applied to the decision-making process, thereby enabling producers to find solutions suited to their needs. The computational time is also a key aspect, since the model finds a near-optimal solution by simulating a vast number of alternatives in a very short period of time. All this is translated in a contribution to the improvement of the efficiency and flexibility of the decision-making processes in aquaculture production, both regarding strategic and operative decisions.

Lastly, it is mandatory to consider some limitations and future lines of research as, for example, the incorporation of elements of fuzzy logic to introduce into the model the vagueness of any subjective judgment and the increase of the number of cages that would allow producers to make long-term planning in major aquaculture farms. This points to the need for more research studies on this line and sets out the future direction of them.

Acknowledgements This paper is part of the MedAID project which has received funding from the European Union's H2020 program under Grant Agreement 727315. The authors also wish to thank the IberoAmerican Program for the Development of Science and Technology, CYTED, and the Red Iberoamericana BigDSSAgro (Ref. P515RT0123) for their support of this work.

\section{References}

Abdou, K., Aubin, J., Romdhane, M., Le Loc'h, F., \& Lasram, F. (2017). Environmental assessment of seabass (Dicentrarchus labrax) and seabream (Sparus aurata) farming from a life cycle perspective: A case study of a Tunisian aquaculture farm. Aquaculture, 471, 204-212. https://doi.org/10.1016/j.aquac ulture.2017.01.019.

Abraham, A., Jain, C., \& Goldberg, R. (2005). Evolutionary multiobjetive optimization: Theoretical advances and applications. Berlin: Springer.

Atia, D., Fahmy, F., Ahmed, N., \& Dorrah, H. (2012). Optimal sizing of a solar water heating system based on a genetic algorithm for an aquaculture system. Mathematical and Computer Modelling, 55(3-4), 1436-1449. https://doi.org/10.1016/j.mcm.2011.10.022.

Bjørndal, T., Lane, D., \& Weintraub, A. (2004). Operational research models and the management of fisheries and aquaculture: A review. European Journal of Operational Research, 156(3), 533-540. https:// doi.org/10.1016/s0377-2217(03)00107-3.

Blum, C., \& Roli, A. (2003). Metaheuristics in combinatorial optimization. ACM Computing Surveys, 35(3), 268-308. https://doi.org/10.1145/937503.937505. 
Boyd, C. E. (2015). Overview of aquaculture feeds: Global impacts of ingredient use. In A. Davids (Ed.), Feed and feeding practices in aquaculture (pp. 3-25). Sawston: Woodhead Publishing Series in Food Science, Technology and Nutrition.

Brett, J. R. (1979). Environmental factors and growth. Fish Physiology, 8, 599-675. https://doi.org/10.1016/ S1546-5098(08)60033-3.

Brown, R. C. (2003). Genetic management and selective breeding in farmed populations of gilthead seabream, Sparus aurata. Ph.D. Thesis, University of Stirling, UK. Retrieved April 9, 2019, from http:// hdl.handle.net/1893/74.

Cabral, J. B., Luczywo, N. A., \& Zanazzi, J. L. (2016). Scikit-Criteria: Colección de Métodos de Análisis Multi-Criterio Integrado Al Stack Científico de Python. XLV Jornadas Argentinas de Informática E Investigación Operativa (45JAIIO)-XIV Simposio Argentino de Investigación Operativa (SIO), 59-66. http://hdl.handle.net/10915/58577.

Casini, M., Mocenni, C., Paoletti, S., \& Pranzo, M. (2015). Decision support system development for integrated management of European coastal lagoons. Environmental Modelling and Software, 64, 47-57. https://doi.org/10.1016/j.envsoft.2014.11.008.

Chen, P., Wiley, E., \& Mcnyset, K. (2006). Ecological niche modeling as a predictive tool: Silver and bighead carps in North America. Biological Invasions, 9(1), 43-51. https://doi.org/10.1007/s1053 0-006-9004-X.

Cobo, A., Llorente, I., \& Luna, L. (2015). Swarm intelligence in optimal management of aquaculture farms. In L. M. Plà-Aragonés (Ed.), Handbook of operations research in agriculture and the agri-food industry. Springer.

Cobo, Á., Llorente, I., Luna, L., \& Luna, M. (2018). A decision support system for fish farming using particle swarm optimization. Computers and Electronics in Agriculture. https://doi.org/10.1016/j.compa g.2018.03.036.

D’Angelo, D., Meyer, J., Howard, L., Gregory, S., \& Ashkenas, L. (1995). Ecological uses for genetic algorithms: Predicting fish distributions in complex physical habitats. Canadian Journal of Fisheries and Aquatic Sciences, 52(9), 1893-1908. https://doi.org/10.1139/f95-782.

Dapueto, G., Massa, F., Costa, S., Cimoli, L., Olivari, E., Chiantore, M., et al. (2015). A spatial multicriteria evaluation for site selection of offshore marine fish farm in the Ligurian Sea, Italy. Ocean and Coastal Management, 116, 64-77. https://doi.org/10.1016/j.ocecoaman.2015.06.030.

de Verdal, H., Komen, H., Quillet, E., Chatain, B., Allal, F., Benzie, J., et al. (2017). Improving feed efficiency in fish using selective breeding: A review. Reviews In Aquaculture, 10(4), 833-851. https://doi. org/10.1111/raq.12202.

Deb, K., Pratap, A., Agarwal, S., \& Meyarivan, T. (2002). A fast and elitist multiobjective genetic algorithm: NSGA-II. IEEE Transactions on Evolutionary Computation, 6(2), 182-197. https://doi. org/10.1109/4235.996017.

El-Gayar, O., \& Leung, P. (2001). A multiple criteria decision making framework for regional aquaculture development. European Journal of Operational Research, 133(3), 462-482. https://doi.org/10.1016/ s0377-2217(00)00183-1.

Ernst, D., Bolte, J., \& Nath, S. (2000). AquaFarm: Simulation and decision support for aquaculture facility design and management planning. Aquacultural Engineering, 23(1-3), 121-179. https://doi. org/10.1016/s0144-8609(00)00045-5.

European Commission. (2008). Commission Regulation No 889/2008 of 5 September 2008 laying down detailed rules for the implementation of Council Regulation (EC) No 834/2007 on organic production and labelling of organic products with regard to organic production, labelling and control. Including amendments. Retrieved April 9, 2019, from https://eur-lex.europa.eu/legal-content/EN/ TXT/?qid=1515078877100\&uri=CELEX:02008R0889-20180101.

Figueira, J., Greco, S., \& Ehrogott, M. (2005). Multiple criteria decision analysis: State of the art surveys. New York, NY: Springer Science + Business Media, Inc.

Goddard, S. (1996). Feed management in intensive aquaculture. New York: Chapman \& Hall.

Goldberg, D. (2012). Genetic algorithms in search, optimization, and machine learning. Boston: Addison-Wesley.

Goldberg, D., \& Holland, J. (1988). Genetic algorithms and machine learning. Machine Learning, 3(23), 95-99. https://doi.org/10.1023/A:1022602019183.

Grigorakis, K. (2010). Effects of nutrition and aquaculture practices on fish quality. In C. Alasalvar, F. Shahidi, K. Miyashita, \& U. Wanasundara (Eds.), Handbook of seafood quality, safety and health applications (pp. 82-95). Hoboken: Wiley-Blackwell.

Hormiga, J., Almansa, E., Sykes, A., \& Torres, N. (2010). Model based optimization of feeding regimens in aquaculture: Application to the improvement of Octopus vulgaris viability in captivity. Journal of Biotechnology, 149(3), 209-214. https://doi.org/10.1016/j.jbiotec.2009.12.008. 
Hwang, C. L., \& Yoon, K. (1981). Multiple attribute decision making: Methods and applications. New York: Springer. https://doi.org/10.1007/978-3-642-48318-9.

Ishibuchi, H., Tsukamoto, N., \& Nojima, Y. (2008). Evolutionary many-objective optimization: A short review. In Proceedings of the congress on evolutionary computation (IEEE world congress on computational intelligence).

Ishizaka, A., \& Labib, A. (2011). Review of the main developments in the analytic hierarchy process. Expert Systems with Applications, 38(11), 14336-14345. https://doi.org/10.1016/j. eswa.2011.04.143.

Kousoulaki, K., Saether, B., Albrektsen, S., \& Noble, C. (2015). Review on European sea bass (Dicentrarchus labrax, Linnaeus, 1758) nutrition and feed management: A practical guide for optimizing feed formulation and farming protocols. Aquaculture Nutrition, 21(2), 129-151. https://doi. org/10.1111/anu.12233.

Lamata, M., Liern, V., \& Pérez-Gladish, B. (2016). Doing good by doing well: A MCDM framework for evaluating corporate social responsibility attractiveness. Annals of Operations Research, 267(1-2), 249-266. https://doi.org/10.1007/s10479-016-2271-8.

Lee, C. (2018). A review of applications of genetic algorithms in operations management. Engineering Applications of Artificial Intelligence, 76, 1-12. https://doi.org/10.1016/j.engappai.2018.08.011.

Lembo, G., Jokumsen, A., Spedicato, M., Facchini, M., \& Bitetto, I. (2018). Assessing stakeholder's experience and sensitivity on key issues for the economic growth of organic aquaculture production. Marine Policy, 87, 84-93. https://doi.org/10.1016/j.marpol.2017.10.005.

Liu, S., Tai, H., Ding, Q., Li, D., Xu, L., \& Wei, Y. (2013). A hybrid approach of support vector regression with genetic algorithm optimization for aquaculture water quality prediction. Mathematical and Computer Modelling, 58(3-4), 458-465. https://doi.org/10.1016/j.mcm.2011.11.021.

Llorente, I., \& Luna, L. (2013). The competitive advantages arising from different environmental conditions in seabream, Sparus aurata, production in the mediterranean sea. Journal of the World Aquaculture Society, 44(5), 611-627. https://doi.org/10.1111/jwas.12069.

Llorente, I., \& Luna, L. (2014). Economic optimisation in seabream (Sparus aurata) aquaculture production using a particle swarm optimisation algorithm. Aquaculture International, 22(6), 18371849. https://doi.org/10.1007/s10499-014-9786-2.

Luna, L. (2002). Economic analysis of finfish mariculture operations in Spain. Aquaculture Economics \& Management, 6(1-2), 65-79. https://doi.org/10.1080/13657300209380304.

Luna, M., Llorente, I., \& Cobo, Á. (2019). Integration of environmental sustainability and product quality criteria in the decision-making process for feeding strategies in seabream aquaculture companies. Journal of Cleaner Production, 217, 691-701. https://doi.org/10.1016/j.jclepro.2019.01.248.

MAPAMA. (2012). Estudio de la cadena de valor y formación de precios de la Dorada de acuicultura. Madrid: Observatorio de Precios de los Alimentos.

Mardle, S., Pascoe, S., \& Tamiz, M. (2000). An investigation of genetic algorithms for the optimization of multi-objective fisheries bioeconomic models. International Transactions In Operational Research, 7(1), 33-49. https://doi.org/10.1111/j.1475-3995.2000.tb00183.x.

Michalewicz, Z. (1996). Genetic algorithms + data structures = evolution programs. Berlin: Springer.

Parks, G. (1996). Multiobjective pressurized water reactor reload core design by nondominated genetic algorithm search. Nuclear Science and Engineering, 124(1), 178-187. https://doi.org/10.13182/ nse96-a24233.

Pelletier, N., \& Tyedmers, P. (2007). Feeding farmed salmon: Is organic better? Aquaculture, 272(1-4), 399-416. https://doi.org/10.1016/j.aquaculture.2007.06.024.

Saaty, R. W. (1987). The analytic hierarchy process-What it is and how it is used. Mathematical Modelling, 9, 161-176. https://doi.org/10.1016/0270-0255(87)90473-8.

Saaty, T. L. (1980). The analytic hierarchy process. New York: McGraw-Hill.

Schulstad, G. (1997). Design of a computerized decision support system for hatchery production management. Aquacultural Engineering, 16(1-2), 7-25. https://doi.org/10.1016/s0144-8609(96)01016-3.

Shahidi, F., \& Alasalvar, C. (2010). Marine oils and other marine nutraceuticals. In C. Alasalvar, F. Shahidi, K. Miyashita, \& U. Wanasundara (Eds.), Handbook of seafood quality, safety and health applications (pp. 444-454). Hoboken: Wiley-Blackwell.

Shih, Y. (2017). Integrated GIS and AHP for marine aquaculture site selection in Penghu Cove in Taiwan. Journal of Coastal Zone Management. https://doi.org/10.4172/2473-3350.1000438.

Siriwardene, N., \& Perera, B. (2006). Selection of genetic algorithm operators for urban drainage model parameter optimisation. Mathematical and Computer Modelling, 44(5-6), 415-429. https://doi. org/10.1016/j.mcm.2006.01.002. 
Sørensen, M. (2012). A review of the effects of ingredient composition and processing conditions on the physical qualities of extruded high-energy fish feed as measured by prevailing methods. Aquaculture Nutrition, 18(3), 233-248. https://doi.org/10.1111/j.1365-2095.2011.00924.x.

Stafford, R. (2008). A computational approach to ecological and economic sustainable harvest management strategies in a multi-species context, with implications for cod recovery plans. Ecological Informatics, 3(1), 105-110. https://doi.org/10.1016/j.ecoinf.2007.12.001.

Stagnitti, F. (1997). A decision support tool for aquaculture. Environmental Modelling and Software, 12(23), 229-236. https://doi.org/10.1016/s1364-8152(97)00015-7.

Triantaphyllou, E. (2000). Multi-criteria decision making methods. Dordrecht: Kluwer Academic Publishers. https://doi.org/10.1007/978-1-4757-3157-6.

Tzeng, G. H., \& Huang, J. J. (2011). Multiple attribute decision making. New York: Chapman and Hall/ CRC. https://doi.org/10.1201/b11032.

Vieira, L., \& Amaral, F. (2016). Barriers and strategies applying Cleaner Production: A systematic review. Journal of Cleaner Production, 113, 5-16. https://doi.org/10.1016/j.jclepro.2015.11.034.

Wang, L., Chu, J., \& Wu, J. (2007). Selection of optimum maintenance strategies based on a fuzzy analytic hierarchy process. International Journal of Production Economics, 107(1), 151-163. https://doi. org/10.1016/j.ijpe.2006.08.005.

Zander, K., \& Feucht, Y. (2017). Consumers' willingness to pay for sustainable seafood made in Europe. Journal of International Food \& Agribusiness Marketing, 30(3), 251-275. https://doi. org/10.1080/08974438.2017.1413611.

Zhou, C., Lin, K., Xu, D., Chen, L., Guo, Q., Sun, C., et al. (2018). Near infrared computer vision and neuro-fuzzy model-based feeding decision system for fish in aquaculture. Computers and Electronics in Agriculture, 146, 114-124. https://doi.org/10.1016/j.compag.2018.02.006.

Zitzler, E., Deb, K., \& Thiele, L. (2000). Comparison of multiobjective evolutionary algorithms: Empirical results. Evolutionary Computation, 8(2), 173-195. https://doi.org/10.1162/106365600568202.

Publisher's Note Springer Nature remains neutral with regard to jurisdictional claims in published maps and institutional affiliations. 